\title{
Endodontic Output in Public Healthcare under Different Instrumentation Techniques: A Quantitative and Qualitative Study
}

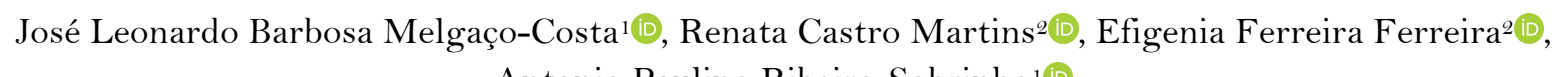

Antonio Paulino Ribeiro-Sobrinho1 ${ }^{10}$

${ }^{1}$ Department of Restorative Dentistry, Faculty of Dentistry, Federal University of Minas Gerais, Belo Horizonte, MG, Brazil.

${ }^{2}$ Department of Social and Preventive Dentistry, Federal University of Minas Gerais, Belo Horizonte, MG, Brazil.

Correspondence: Antônio Paulino Ribeiro-Sobrinho, Av Antônio Carlos, 6627, sl.3312, Pampulha, Belo Horizonte, Minas Gerais, Brazil. 31270-901. E-mail: sobrinho.bhz@gmail.com

Academic Editor: Yuri Wanderley Cavalcanti

Received: 21 November 2020 / Review: 19 March 2021 / Accepted: 05 April 2021

How to cite: Melgaço-Costa JLB, Martins RC, Ferreira EF, Ribeiro-Sobrinho AP. Endodontic output in public healthcare under different instrumentation techniques: a quantitative and qualitative study. Pesqui Bras Odontopediatria Clín Integr. 2021; 21 :e0239. https://doi.org/10.1590/pboci.2021.122

\begin{abstract}
Objective: To evaluate output of endodontic in oral public healthcare by analyzing differences in instrumentation techniques, quantitative and qualitatively. Material and Methods: Endodontic services were differentiated by instrumentation techniques: hand techniques with stainless steel instruments (SS) or rotary using NiTi rotary instruments. Secondary data on the productivity of 2011 were obtained from the information system. Student's $\mathrm{t}$ and Mann-Whitney tests were used. Qualitative data were based on semistructured interviews, direct observation and field diary. Results: Service I employed SS hand techniques, service II used both techniques, while NiTi rotary system was used in service III. Statistically significant differences were observed in total endodontic productivity, with I presenting more productive results than II $(\mathrm{p}=0.001)$ and III $(\mathrm{p}=0.009)$; III presenting more productive results than II $(\mathrm{p}<0.001)$. Comparisons of endodontic treatment types revealed that I performed more multiradicular tooth treatments than did II and III $(\mathrm{p}=0.005)$, and III performed more treatments on biradicular teeth than did I and II $(\mathrm{p}=0.002)$. Qualitative analyses were divided into themes: "perceptions of the service" and "perceptions of the employed instrument". Conclusion: Professional experience and high productivity per hour can be a differential; the use of rotary instrumentation can be useful in solving unmet demands. Perception of endodontists showed that chosen endodontic technique influenced job satisfaction and lack of integrality of the treatment is a problem in secondary care.
\end{abstract}

Keywords: Endodontics; Secondary Care; Health Services Research; Dental Health Services. 


\section{Introduction}

Root canal treatments are performed to prevent or heal apical periodontitis and may use mechanical cleaning and shaping, as well as a three-dimensional obturation, of the root canal space [1]. Rapid technological advances in recent years has resulted in stainless steel (SS) hand instruments giving way to rotary instruments made from a more flexible nickel-titanium (NiTi) alloy. Studies have reported that this new technology can facilitate root canal preparation with a minimal risk of mishaps and can facilitate good-quality root canal filling [Q].

These rotary instruments have also been introduced in the oral public health sector, offering the potential for more efficient and decisive treatments, which increases the number of attended patients and reduces waiting times for endodontic treatment [3].

In 2004, the Brazilian Ministry of Health (MofH) created an oral public health program for secondary care integrated into the healthcare network. This program deployed Dental Specialties Centers (DSC) to address dental care deficits in populations with oral diseases that require treatment, including endodontic infections, periodontal treatments, minor oral surgery, oral diagnosis, and care for patients with special needs. Regarding physical-structural features, DSCs are classified into three types: I (three dental chairs), II (4 to 6 dental chairs), or III (more than 7 dental chairs). DSCs must work 40 hours per week, but the number of professionals by specialty is variable and depends on the epidemiological needs of the population of each city where the service is implemented [4]. These DSCs can contribute to the building of a healthcare network, defined as a set of articulated actions and health services at increasingly complex levels to ensure the integrality of healthcare and contributes to reducing inequality [5].

The incorporation of new technologies in specialized healthcare services in countries with universal coverage is of interest to public health managers. Public health system policies in Brazil have recently begun to encourage research on common oral health problems and the development of technological alternatives to address the demand for certain services and strategies in the Brazilian population [6].

A study evaluating secondary care in oral health in Brazil confirmed previously found results, where the productivity of oral health public services, in general, are low and below the stipulated limits set by the MofH [7], which indicates minimum productivity targets for different types of DSCs to monitor the performance of these centers. The minimum monthly production requirement in endodontic areas is 35 , 60, and 95 procedures per month for DSC types I, II, and III, respectively [4]. Furthermore, statistical analysis of correlations between care productivity and socio-demographic aspects within various Brazilian cities revealed that population size and the human development index (HDI) were correlated, with smaller city size and lower HDI associated with worse performance [7].

Therefore, this quantitative and qualitative study measured the output of endodontic procedures in the Brazilian secondary oral public health system by analyzing differences in instrumentation techniques of three municipalities.

\section{Material and Methods}

\section{Study Design}

This cross-sectional study is a quantitative study with qualitative data added to provide deeper, wider, and fuller answers to the research questions. The quantitative and qualitative data collections were conducted in three cities in the state of Minas Gerais, Brazil, located close to the capital of the state in its metropolitan area. These cities presented one type II DSC each, similar socioeconomic indicators and were selected by 
convenience because their secondary oral health services were well organized, have similar physical-structural features and were differentiated by the instruments used by professionals during root canal shaping (SS hand instruments or NiTi rotary instruments).

\section{Quantitative Study}

This study used endodontic productivity data obtained from DSC in three selected cities. Secondary data on the endodontic productivity of 2011 of the three cities were collected, according to the National Register of Health Institutions (CNES in Portuguese) from SUS's Outpatient Information System, using the DATASUS system by a single researcher. This system only shows the total production without pointing out the number of professionals who have worked to achieve these numbers. The Brazilian MofH defines as endodontic procedures performed for secondary care: endodontic treatment and retreatment of uniradicular, biradicular, and multiradicular tooth; endodontic treatment of primary teeth and the sealing of root perforation [7]. Data related to the cities' characteristics (population sizes, HDI) in 2010, and Gini Index, in 2003, were obtained from the Brazilian Institute of Geography and Statistics [8].

Descriptive statistics using IBM SPSS Statistics for Windows, version 19.0 (IBM Corp., Armonk, NY) were obtained for all variables. Endodontic treatments performed on uniradicular, biradicular, and multiradicular teeth were also analyzed according to city. The Kolmogorov-Smirnov test was used to determine the distribution of the resulting data. Mann-Whitney $(\mathrm{p}<0.001)$ and Student's $t(p>0.05)$ tests were used to analyze variables with non-parametric and parametric distributions, respectively. The confidence level was set at $95 \%$.

\section{Qualitative Study}

Qualitative data were based on semi-structured interviews, direct observations, and field diary [9] to clarify and explain quantitative results. All participants (6 endodontists) signed the Free and Informed Consent Form, which explained the purpose of the study to the patient. The qualitative data collection was performed concomitantly with the collection of the quantitative data in the DSCs in three selected cities.

The interviews were referred to endodontists who had been working in secondary care for at least one year in three selected cities. A semi-structured interview format with a pre-determined set of questions was used and the questions reflected on professional education, description of demand for dental services and dental professionals' practices (type of instrument to shape the root canal: SS or NiTi), and working conditions. A pretest was conducted with one endodontist, who had already worked in one of the DSCs of the cities and who did not participate in the main study, in order to adjust the research instrument.

All interviews were conducted by the same researcher in a quiet and private room, after a period of time of professional work. Each interview lasted approximately one hour. The researcher was not a clinician in any of the evaluated services and only had contact with the participants during the interview. All interviews were audiotaped and transcribed verbatim by the researcher.

Direct observations of the services were noted in the field diary and consisted of facts concerning the work process of the units and/or the interview and observations related to the problem under investigation [9]. Notes were made in conversations with managers, dentists, and dental assistants, such as: number of endodontists in each DSC and daily workload per endodontist. Data were analyzed using content analysis [9]. Several readings of the verbatim transcripts and field notes and listening to the audio recordings were 
performed to extract expressions and words leading to the central themes. The researchers discussed disagreements until a consensus was reached.

Ethical Clearance

This study was approved by the Human Research Ethics Committee at Universidade Federal de Minas Gerais, Brazil (Protocol ETIC 07 18.0.203.000-11).

\section{Results}

Quantitative Findings

No data are missing from this study. The cities had different population sizes: city I had 378,089 inhabitants, city II and III had 158,956 and 45,499 inhabitants, respectively. The cities showed similar social indicators. HDI and Gini Index of the three cities were $0.749,0.704,0.730$, and $0.36,0.33,0.42$, respectively.

Total endodontic procedures performed in three DSCs, according to those procedures considered by Brazilian MofH, showed a yearly productivity for service I, II, and III of equal to 865, 466, and 643 endodontic procedures, respectively. Dental professionals within the largest (service I) used the SS hand instruments to perform endodontic shaping, while those within the smallest (III) and intermediate (II) services used NiTi rotary instruments (ProTaper system, Dentsply Sirona) and both technologies, respectively.

Through the field diary, it was possible to identify the number of endodontists working in each DSC of the selected cities, as well as their daily workload. Table 1 shows the monthly mean of productivity and the productivity per hour of the endodontists in the DSC of each selected city. Monthly, the productivity for services I, II, and III was 72.08, 38.83, and 53.33, respectively, while the productivity per hour of DSC I (O.45) was 2.8 and 1.4 times higher than DSC II (0.16) and DSC III (0.33), respectively; DSC III was also 2.06 times higher productivity than DSC II.

Table 1. Productivity per hour of the endodontists in the three services.

\begin{tabular}{ccccccc}
\hline Services & $\begin{array}{c}\text { Total Endodontic } \\
\text { Procedures }^{\mathbf{a}}\end{array}$ & $\begin{array}{c}\text { Monthly Mean } \\
\text { of Productivity }^{\mathbf{b}}\end{array}$ & $\begin{array}{c}\text { Number of } \\
\text { Endodontists }^{\mathbf{c}}\end{array}$ & $\begin{array}{c}\text { Daily } \\
\text { Workload }^{\mathbf{d}} \text { (h) }\end{array}$ & $\begin{array}{c}\text { Monthly } \\
\text { Workload }^{\mathbf{~}} \text { (h) }\end{array}$ & $\begin{array}{c}\text { Productivity } \\
\text { per Hour }^{\mathbf{f}}\end{array}$ \\
\hline I & 865 & 72.08 & 1 & 8 & 160 & 0.45 \\
II & 466 & 38.83 & 3 & 12 & 240 & 0.16 \\
III & 643 & 53.58 & 2 & 8 & 160 & 0.33 \\
\hline
\end{tabular}

aTotal endodontic procedures performed in 2011 in each service; ${ }^{\text {b} T o t a l ~ e n d o d o n t i c ~ p r o c e d u r e s ~ d i v i d e d ~ b y ~} 12$ months; ${ }^{\mathrm{c} N u m b e r}$ of endodontists working in each service, according to field diary; dDaily workload: number of shifts worked per day of each professional multiplied by 4 (each shift is equivalent to 4 hours). In service I, the professional works a double shift ( 2 shifts per day); ${ }^{\mathrm{e}}$ Monthly workload: Number of hours worked per day multiplied by 5 days of the week, multiplied by 4 weeks of the month; ${ }^{\mathrm{f}}$ Monthly mean divided by monthly workload (b/e).

Descriptive statistics for endodontic treatments performed in uniradicular, biradicular and multiradicular teeth in each of the three services are shown in Table 2. In every DSC, the total productivity of endodontic treatment of multiradicular teeth was greater than the uniradicular and biradicular teeth.

Table 2. Descriptive statistics of endodontic treatments performed in three services.

\begin{tabular}{|c|c|c|c|c|c|c|c|c|c|}
\hline \multirow{3}{*}{ Service } & \multicolumn{9}{|c|}{ Endodontic Treatment } \\
\hline & \multicolumn{3}{|c|}{ Uniradicular Teeth } & \multicolumn{3}{|c|}{ Biradicular Teeth } & \multicolumn{3}{|c|}{ Multiradicular Teeth } \\
\hline & $\mathrm{N}$ & Monthly Mean & $\mathrm{SD}$ & $\mathrm{N}$ & Monthly Mean & SD & $\mathrm{N}$ & Monthly Mean & SD \\
\hline I & 221 & 18.42 & 14.132 & 132 & 11 & 7.032 & 442 & 36.83 & 22.554 \\
\hline II & 144 & 12.00 & 7.410 & 83 & 6.92 & 2.906 & 222 & 18.50 & 11.882 \\
\hline III & 145 & 12.08 & 6.127 & 142 & 11.83 & 3.713 & 228 & 24.83 & 4.970 \\
\hline
\end{tabular}

SD: Standard Deviation. 
There were statistically significant differences in total productivity among the services (Table 3). Service I showed a higher productivity than those of service II $(p=0.001)$ and service III $(p=0.009)$, while service III had a higher productivity than that of service II $(\mathrm{p}<0.001)$.

When comparing treated tooth types, service I performed significantly more endodontic treatments of multiradicular teeth than services II and III $(\mathrm{p}=0.005)$. In relation to the endodontic treatments of biradicular teeth, service III performed significantly more treatments on this tooth type when compared to service II $(\mathrm{p}=0.002)$, as shown in Table 3 .

Table 3. Analytical comparison of productions of endodontic treatments among the three services.

\begin{tabular}{|c|c|c|c|c|c|c|c|c|}
\hline \multirow{3}{*}{ Services } & \multicolumn{8}{|c|}{ Endodontic Treatment } \\
\hline & \multicolumn{2}{|c|}{ Uniradicular Teeth } & \multicolumn{2}{|c|}{ Biradicular Teeth } & \multicolumn{2}{|c|}{ Multiradicular Teeth } & \multicolumn{2}{|c|}{ Total } \\
\hline & Test value & p-value & Test value & p-value & Test value & p-value & Test value & p-value \\
\hline I x II & $47.000^{* * *}$ & 0.15 & $1.859^{*}$ & 0.08 & $23.000 * *$ & 0.005 & $2423.000 * *$ & 0.001 \\
\hline I x III & $47.000 * *$ & 0.15 & $-0.363^{*}$ & 0.72 & $23.500^{* *}$ & 0.005 & $1244.500 * *$ & 0.009 \\
\hline II x III & $-0.030^{*}$ & 0.98 & $-3.612^{*}$ & 0.002 & -1.703 & 0.10 & $814.000^{* *}$ & $<0.001$ \\
\hline
\end{tabular}

*Student's t test; **Mann-Whitney test.

Qualitative Findings

Of the six endodontists who worked in the DSCs of the three cities, four (two from service II and two from service III) employed NiTi rotary instruments to perform root canal shaping, while two (one from service I and one from service II) used SS hand instruments. In every evaluated DSCs, the auxiliary teams were common to every service, being shared for all specialists of the DSC and not just for the endodontists.

Five professionals had completed post-graduate studies in Endodontics and only one had not (service I), despite being the most experienced of the group with the longest time in the field since graduation. He worked 8 hours per day and used only SS hand instruments to shape the root canals. Two professionals were specialized in other areas as well (one from service II and one from service III), and another (service II) had an M.S. and a Ph.D. in Endodontics. The time working at the public health service in endodontics ranged from 01 to 10 years.

The analyses of interview contents were divided into two core themes: "perceptions of the service" and "perceptions of the employed instrument", together with the topics related to each general theme. The "perceptions of the dental service" included the time spent in each session, the number of sessions to conclude the endodontic treatments, and the organization of the workload. The time per session spent by each professional was similar in the different services (field diary), at one hour on the average. Conversely, the number of sessions to conclude the endodontic treatment varied depending on the specific treated teeth. The chosen endodontic technique only interfered in the number of sessions in the molar groups.

In uniradicular teeth, it was observed that endodontic treatment was almost always finished during the same appointment. Endodontic treatment of premolars presented an average of 1-2 sessions (one session being more common), regardless of which instrumentation technique was selected. The mean time to perform the treatment of molar teeth using rotary and hand instruments was 1-2 visits and 1-3 visits, respectively.

Regarding the perceptions of the organization of the workload, the reports showed an absence of a long waiting list, regardless of which endodontic instrumentation technique was used. The failure to continue treatment, resulting in a poor resolution of the patients' needs, was reported as a problem associated with the organization of the public health service: “(...) the problem is that often after the endodontic treatment there is a need to make a prosthesis, and they have no conditions. (...) many times a patient must extract a tooth that I did endodontic treatment on! (...) There is no continuation (...)” (Endodontist 1). 
The "perceptions of the employed instrument" was related to the improvement in the quality of the treatments, the insertion of the technology within the dental service, and training courses.

All dentists reported a high degree of satisfaction with the endodontic treatments performed, pointing to the minimization of iatrogenesis and instrumentation deviations, as well as tridimensional fillings verified by radiographs, as items used by them to determine their satisfaction. The satisfaction of professionals was more explicit and related to the instruments used: “(...) root canal treatment performed with hand instruments presents good results (...), but with the rotary instruments it is different, because there is no professional fatigue, (...) the shaping results facilitates the filling of root canals. (...) today I think the quality of my treatments with this technology is different" (Endodontist 4).

"Very happy because (...) I have equipment here that facilitates my work, like the rotary system. (...) So I think the final work has a good quality" (Endodontist 5).

The professionals' training with rotary instruments in the two cities (II and III) that used these instruments was different: in one, no training was offered, while in the other, an endodontist trained the team.

In the DSC where the rotary system was not used, the dentist asked for a training course as a requirement for adherence to the technology. However, the dentist in the DSC where the rotary system was being used voiced his insatisfaction with the lack of training sessions offered by healthcare services: "They (the management) did not offer, they did not help. (...) They want to use it to increase production! Because if I produce a lot with hand instruments, I can continue!" (Endodontist 2).

"A training! And I said so, you have to train me, because I've never worked with that, but I have a notion" (Endodontist 1).

\section{Discussion}

One study on Brazilian oral public healthcare services confirmed that the best performance of secondary care is related to an increase in population size [7]. This study examined centers as a whole, including all specialties offered as healthcare services. However, to our knowledge, no other study has separately assessed endodontics.

Dental caries is still a prevalent oral health problem in Brazilian adults, and the frequency of decay often requires endodontic treatment, increasing the demand for endodontics. Results indicated that service I had a higher production than that of services II and III, highlighting the importance of considering the demand for services as an epidemiological criterion in the distribution of human resources for health [10].

Results of qualitative findings, which determined the productivity in endodontics per hour, showed that the professional of the service I was more productive than the professionals of the services II and III. This professional, despite not having a specialist's degree, had worked for a long time in endodontics, demonstrating that more experienced professionals [11] with longer working time in the public healthcare service can explain these findings, whereas the high turnover of professionals harms the longitudinality and continuity of healthcare. Human resources are an overriding element to achieving good performance and are essential for a healthcare service to function properly [12]. Therefore, the most important thing in order to work well in Endodontics is not only the instrumentation technique, but also, if you have a good technique and can work well with it, you can be as productive as, or even more productive than, a fast technology. However, technological innovations are crucial for advancements in clinical dentistry, and the use of the good techniques have been linked with an increased capacity of dentists to produce more dental services per unit of time [13]. 
Furthermore, service III performed more endodontic procedures than did service II, being two times more productive even with its lower population size. The use of exclusive NiTi rotary instruments to shape root canals may have favored these findings; however, conducting procedure also depends on other aspects of the offer, such as the number of DSC and dentists/specialists [10,12], professional skills, working conditions (inputs and technologies available), and demand (specific need of population), in addition to service criteria and priorities.

Donabedian [14] considers that the minimum structural conditions of health services (e.g., financial, human, physical, organizational resources) are necessary and good work process increases the probability of good outcomes. However, they are still not enough to ensure high-quality care. Otherwise, a fragmented healthcare model will persist, which does not respond to the demands of the population, neither continuously nor longitudinally [15]. Moreover, it is imperative for clinical organizations to follow protocols and to organize the flow for the referral and counter-referral of primary to secondary care [16]. Then, the evaluation of the service's work process and the use of protocols in endodontic in the evaluated DSC in this study could justify better output in the less structured service and with less technological resources. However, these variables were not assess and they could be the focus of future studies.

The results showed that molars continued to be the group of teeth that most frequently received endodontic treatment, which is in agreement with another study in the literature [17]. This observation is due to the tendency for patients to keep more of their natural teeth [18], particularly molars, which are currently preserved with endodontic treatment [19]. Furthermore, the molars have a more complex anatomy [19] and spend more time under cariogenic challenge.

Studies have demonstrated that NiTi rotary instrumentation has several advantages over SS hand instrumentation, including better modeling and shortened treatment time [20]. Mechanical root canal preparation is reportedly the most time-consuming procedure [18]. Historically, endodontic treatment has been extended to several appointments; however, the introduction of new technologies, such as NiTi instruments, has reduced the number of appointments and allows for treatment in a single visit [21]. One Australian survey [20] noted that, in $80 \%$ of the rotary instrumentation, users reported more rapid preparation of root canals. These findings were noted in both direct observations and field diaries [9], in which the mean time to perform the treatment of molar teeth using rotary instrumentation was lower than using hand instruments.

The reports on the absence of long waiting lists in DSC, regardless of the endodontic technique of instrumentation, should be carefully analyzed. This fact can be explained by the tendency of overestimated results in self-assessment studies. In general, patients referred from primary care to specialized endodontic treatment were subjected to a long waiting time [22,23]. DSCs deployment in municipalities in which primary healthcare is not well structured is not recommended, since secondary care would be exposed to free demand and the performing of basic procedures that [24], which can influence the productivity of the DSCs.

In this study, one problem cited as the lack of organization of the public health service was the failure to resolve patients' needs after the conclusion of endodontic treatment. This report may be linked to problems with interfaces between secondary and primary care, given that endodontic treatment is an intermediary procedure and has no end in itself [22]. Thus, the way in which people obtain access to primary care must be strengthened, and the continuity of care in specialized treatment must exist without barriers, including efficient mechanisms to regulate the flow of assistance to other levels of care in order to achieve integrality $[23]$. 
Another perception of the use of NiTi rotary instrumentation by endodontists was associated with the satisfaction regarding positive results of the treatment, revealing improved results and quality of treatments, which corroborates other studies [25,26]. However, one study [27] compared the survival rates of endodontic treatment performed by using instrumentation with SS hand files versus those performed using more contemporary techniques (instrumentation with hand and rotary nickel-titanium files) and it did not observe difference between the two groups in terms of survival.

Despite all these highlighted advantages and to be well established in the literature that NiTi files are safer than SS files and the separation rate of NiTi rotary instruments in currently very low [28], it is necessary to include pre-clinical training sessions in order to introduce the use of these instruments in endodontic clinical practice [20]. Qualitative results from this study indicated that the DSC professionals evaluated in this study agreed with findings from the literature that indicate the need for preclinical training. The successful introduction of new technologies into routine clinical practice requires effective products, as well as appropriate educational training, in an attempt to underscore their usefulness to practitioners. Resource allocation in any healthcare system should be cost-effective. Therefore, analysis of alternative intervention should also consider their relative costs and benefits to determine their relative efficiency [29].

In this way, comparing root canal treatments performed before and after NiTi rotary technique education regarding instrumentation costs and the number of instrumentation sessions in a public dentistry service revealed that significantly fewer instrumentation sessions were required when earlier training was performed, which resulted in lower costs, providing a more cost-effective implementation [30]. Studies have shown that the adoption of NiTi rotary instruments in endodontics varies among professionals; however, continuing education programs that include pre-clinical training sessions are vital for adherence to technological innovations [20,26].

In this study, the use of information systems for health and secondary data collection was a limiting factor, but it was consistent with our goals. One advantage of these systems is the quick capture of information, which provides managers an indispensable tool for making decisions. In addition to this limitation, the data used for analysis included procedures performed in this study, which can interfere in the data recording, in either overreporting or underreporting, since MofH takes only the complete endodontic treatments into account, not punctuating intermediate procedures [7]. It should be noted that, between endodontic treatment sessions, complications may occur, such as dental fracture, loss of the dental element, or treatment abandoned by patient, because the pain had been relieved. Furthermore, information bias also can be highlighted as limitations in the present study by the tendency of the professionals to overestimate their self-assessment results

It is also true that "Endodontic productivity" depends on a myriad of factors (e.g.: experience of the providers, availability of endodontists, ratio of general dentists to specialists, economic and social factors). However, this study focused on the type of endodontic technique used in the service. Furthermore, the increased number of qualitative studies in recent years adds an important dimension to the evaluation of actions in oral health, mainly in the public health services, by producing knowledge gained from dental professionals' experience.

\section{Conclusion}

The use of rotary instrumentation in the services of secondary oral public healthcare may be of great use in solving unmet endodontic demands, but the professional experience and high productivity per hour can 
be a differential to the lack of technologies. Regarding the qualitative analysis, the perception of endodontists showed that the chosen endodontic technique influenced job satisfaction, which was more positive among the professionals that use the rotary instruments, and the lack of integrality of the treatment was reported as a problem in secondary care.

\section{Authors' Contributions}

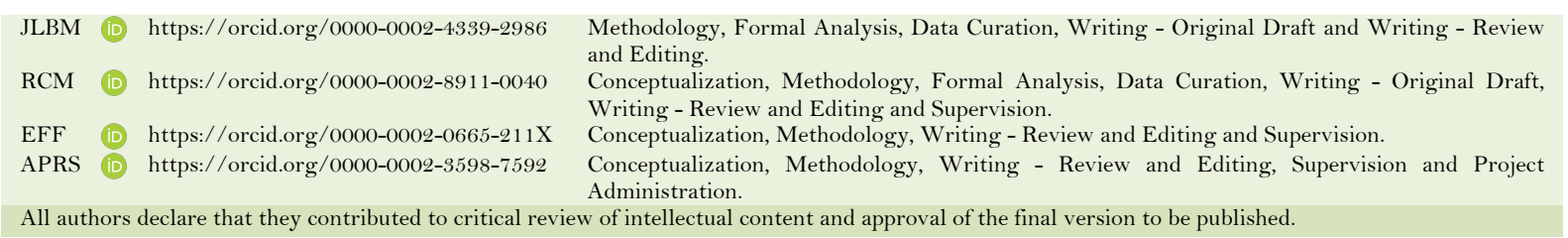

\section{Financial Support}

This study was financed in part by the Conselho Nacional de Desenvolvimento Científico e Tecnológico - CNPq (Grant 307512/2018-5), Coordenação de Aperfeiçoamento de Pessoal de Nível Superior - Brasil (CAPES) - Finance Code oo1, Fundação de Amparo à Pesquisa do Estado de Minas Gerais (FAPEMIG), and Pró-Reitoria de Pesquisa da Universidade Federal de Minas Gerais (PRPq-UFMG).

\section{Conflict of Interest}

The authors declare no conflicts of interest.

\section{Data Availability}

The data used to support the findings of this study can be made available upon request to the corresponding author.

\section{References}

[1] Koch M. On implementation of an endodontic program. Swed Dent J Suppl 2013; (230):9-97.

[2] Schafer E, Burklein S. Impact of nickel-titanium instrumentation of the root canal on clinical outcomes: a focused review. Odontology 2012; 100(2):130-6. https://doi.org/10.1007/s10266-012-0066-1

[3] Martins RC, Seijo MOS, Ferreira EF, Paiva SM, Ribeiro Sobrinho AP. Dental students' perceptions about the endodontic treatment performed using NiTi rotary instruments and hand SS files. Braz Dent J 2012; 23(6):729-36. https://doi.org/10.1590/s0103-64402012000600018

[4] Pedrazzi V, Dias KRHC, Rode SM. Oral health in Brazil - Part II: dental specialty centers (CEOs). Braz Oral Res 2008; 22(Suppl 1):18-23. https://doi.org/10.1590/s 1806-83242008000500004

[5] República Federativa do Brasil. Decree 7508 of 28 June 2011, Which Regulates Law 8080 of 19 September 1990, to Provide for the Organization of the Universal Health System (SUS), Health Planning, Health Care, the Structure among the Federation and Other Measures; Republica Federativa do Brasil: Brasilia, Brazil, 2011.

[6] Paim J, Travassos C, Almeida C, Bahia L, Macinko J. The Brazilian health system: history, advances, and challenges. Lancet 2011; 377(9779):1778-97. https://doi.org/10.1016/S0140-6736(11)60054-8

[7] Cortellazi KL, Balbino EC, Guerra LM, Vazquez FL, Bulgareli JV, Ambrosano GM, et al. Variables associated with the performance of Centers for Dental Specialties in Brazil. Rev Bras Epidemiol 2014; 17(4):978-88. https://doi.org/10.1590/1809-4503201400040015

[8] Instituto Brasileiro de Geografia e Estatística (IBGE) [homepage]. Brasília (DF): Censo demográfico; 2010. Available from: http://www.ibge.gov.br/estadosat/perfil.php?sigla=mg. [Accessed on June 10, 2012]. [In Portuguese].

[9] Bauer MW, Gaskell G. Qualitative Research with Text, Image and Sound. Vozes: Petrópolis, Brazil, 2002; p. 374.

[10] Alcalde-Rabanal JE, Nigenda G, Bärnighausen T, Velasco-Mondragón HE, Darney BG. The gap in human resources to deliver the guaranteed package of prevention and health promotion services at urban and rural primary care facilities in Mexico. Hum Resour Health 2017; 15(1):49. https://doi.org/10.1186/s12960-017-0220-5.

[11] Morisaki M, Shozi H. Work study on endodontic treatments by means of practice administration. Dent Jpn 1990; $27(1): 147-53$.

[12] Gonçalves CR, Cruz MT, Oliveira MP, Morais AJD, Moreira KS, Rodrigues CAQ, et al. Human resources: critical factor for primary health networks. Saúde Debate 2014; 38(100):26-34. https://doi.org/10.5935/0103-104.20140012.

[13] Beazoglou T, Heffley D, Brown LJ, Bailit H. The importance of productivity in estimating need for dentists. J Am Dent Assoc 2002; 133(10):1399-1404. https://doi.org/10.14219/jada.archive.2002.0056.

[14] Donabedian A. The quality of care. How can it be assessed? Arch Pathol Lab Med 1997; 121:1145-50. 
[15] Arboit J, Padoin SM, Vieira LB, Paula CC, Costa MC, Cortes LF. Health care for women in situations of violence: discoordination of network professionals. Rev Esc Enferm USP 2017; 51:e03207. https://doi.org/10.1590/S1980-220X2016113303207

[16] Brazil. Ministry of Health. Department of Health Care. Department of Primary Care. Oral Health, Brasília, 2008. Technical Standards and Manuals - Basic Care Notebooks number 17. 92 p.

[17] Scavo R, Lalis RM, Zmener O, Dipietro S, Grana D, Pameijer CH. Frequency and distribution of teeth requiring endodontic therapy in an Argentine population attending a specialty clinic in endodontics. Int Dent J 2011; 61(5):25760. https://doi.org/10.1111/j.1875-595X.2011.00069.x

[18] Bjørndal L, Laustsen MH, Reit C. Root canal treatment in Denmark is most often carried out in carious vital molar teeth and retreatments are rare. Int Endod J 2006; 39(10):785-90. https://doi.org/10.1111/j.1365-2591.2006.01149.x

[19] Bjørndal L, Reit C. The annual frequency of root fillings, tooth extractions, and pulp related procedures in Danish adults 1977-2003. Int Endod J 2004; 37(11):782-8. https://doi.org/10.1111/j.1365-2591.2004.00879.x

[20] Parashos P, Messer HH. Questionnaire survey on the use of rotary nickel-titanium endondontic instruments by Australian dentists. Int Endod J 2004; 37(4):249-59. https://doi.org/10.1111/j.0143-2885.2004.00784.x

[21] Bjørndal L, Reit C. The adoption of new endodontic technology amongst Danish general dental practitioners. Int Endod J 2005; 38(1):52-8. https://doi.org/10.1111/j.1365-2591.2004.00904.x

[22] Magalhães MBP, Oliveira DV, Lima RF, Ferreira EF, Martins RC. Evaluation of secondary care in endodontics at Dental Specialties Centers (DSC). Cien Saude Colet 2019; 24(12):4643-54. https://doi.org/10.1590/1413-812320182412.04112018

[23] Martins RC, Reis CMR, Matta-Machado ATG, Amaral JHL, Werneck MAF, Abreu MHNG. Relationship between Primary and Secondary Dental Care in Public Health Services in Brazil. PLoS ONE 2016; 11(10):e0164986. https://doi.org/10.1371/journal.pone.0164986

[24] Chaves SCL, Barros SG, Cruz DN, Figueiredo ACL, Moura BLA, Cangussu MCT. Brazilian Oral Health Policy: factors associated with comprehensiveness in health care. Rev Saude Publica 2010; 44(6):1005-13. https://doi.org/10.1590/s0034-89102010005000041

[25] Molander A, Caplan D, Bergenholtz G, Reit C. Improved quality of root fillings provided by general dental practitioners educated in nickel-titanium rotary instrumentation. Int Endod J 2007; 40(4):254-60. https://doi.org/10.1111/j.0143-2885.2007.01208.x

[26] Koch M, Eriksson HG, Axelsson S, Tegelberg A. Effect of educational intervention on adoption of new endodontic technology by general dental practitioners: a questionnaire survey. Int Endod J 2009; 42(4):313-21. https://doi.org/10.1111/j.1365-2591.2008.01511.x

[27] Fleming CH, Litaker MS, Alley LW, Eleazer PD. Comparison of classic endodontic techniques versus contemporary techniques on endodontic treatment success. J Endod 2010; 36(3):414-8. https://doi.org/10.1016/j.joen.2009.11.013

[28] Coelho MS, Card SJ, Tawil PZ. Safety assessment of two hybrid instrumentation techniques in a dental student endodontic clinic: a retrospective study. J Dent Educ 2017; 81(3):333-9.

[29] Barnett ML. Decisions, decisions: challenges to the introduction of new technologies to clinical practice. J Dent Res 2002; 81(1):5. https://doi.org/10.1177/002203450208100102

[30] Koch M, Tegelberg A, Eckerlund I, Axelsson S. A cost-minimization analysis (CMA) of root canal treatment before and after education in nickel-titanium rotary technique in general practice. Int Endod $\mathrm{J} 2012$; 45(7):633-41. https://doi.org/10.1111/j.1365-2591.2012.02019.x 